DOI: $10.17805 / z p u .2016 .1 .20$

\title{
Адаптация первокурсников \\ в образовательной среде вуза \\ как период эволюционных преобразований (на примере Ульяновского государственного технического университета)
}

\author{
Т. Л. СТЕНИНА \\ (УЛЬЯНОВСКИЙ ГОСУДАРСТВЕННЫЙ ТЕХНИЧЕСКИЙ УНИВЕРСИТЕТ)
}

Адаптация студентов в контексте педагогики высшей школы рассматривается как результат педагогического взаимодействия субъектов образования, направленный на присвоение студентами (интериоризацию) ценностей профессионального образования. Адаптация студентов происходит в определенном пространственно-временном континууме среде. Если связать среду и субъект адаптации прямой линией управляющих сигналов и линией обратной связи, то получим систему, учитывающую различия между действием и его результатами. Опыт показывает, что подобная системная организация процесса адаптации первокурсников существенно повышает его эффективность.

В статье рассмотрен процесс организации образовательной среды вуза, способствующей приобщению первокурсников к ценностям высшей школы, исторически сложившимся вузовским традициям, адаптации в системе внутренних и внешних каналов коммуникации. Первокурсники, попадая в новую для себя среду высшего учебного заведения, начинают взаимодействовать с ней посредством включения в различные виды деятельности.

Анализ основан на материалах комплексной Программы социокультурной адаптации студентов первого курса в социально-педагогическом пространстве вуза, которая реализуется с 2009 г. в Ульяновском государственном техническом университете, а также дополнительного исследования с участием 475 первокурсников (технические и гуманитарные специальности) вуза. Применение комплекса апробированных в педагогических экспериментах процедур оценки (опрос, анкетирование, включенное наблюдение, фокус-группы) позволило получить наиболее точный результат. Были определены критерии и показатели, иллюстрирующие процесс адаптации первокурсников в когнитивном, мотивационно-ценностном, деятельностном и рефлексивном компонентах.

Сопоставление начального и конечного результатов исследования позволило сделать вывод об эффективности реализации программы.

Ключевые слова: Ульяновский государственный технический университет; адаптация студентов; первокурсник; образовательная среда вуза

\section{BВЕАЕНИЕ}

$\mathrm{B}$ педагогическом сообществе широко обсуждается проблема адаптации первокурсников в контексте изменений парадигмы высшего образования, изменений в требованиях работодателей, предъявляемых выпускникам. Скорость развития новых технологий, появления новых профессий заставляет педагогов искать новые подходы к педагогической деятельности, направленной на содействие адаптации студентов. В современных исследованиях таких авторов, как Н. А. Ермаченко, В. А. Середа, адаптация признается одним из ведущих качеств личности выпускника вуза и рассматривается как «процесс активного и творческого приспособления... к условиям социальной среды, в частности к условиям обучения и воспитания» в вузе (Ермаченко, Середа, 2012: 54).

И. Б. Буянова в своем исследовании процесса социокультурной адаптации студентов, обосновывая образовательную среду учебного заведения как одно из необходимых условий, способствующих адаптации студентов к обучению, отмечает отсутствие 
системного подхода к организации образовательной среды, единичность и спонтанность проводимых мероприятий, направленных на приобщение студентов к вузовской жизни, недостатки практической деятельности вузов (Буянова, 2005).

В системе философско-социологических дисциплин понятие адаптации связано с ее социальной направленностью, т. е. с жизнью в обществе. Так, А. Я. Флиер в работе «Культурогенез» связывает с адаптацией процесс рождения и становления культуры: «Основной механизм культурогенеза на его микродинамическом уровне видится в процессах адаптации человеческих коллективов к совокупности природных и исторических условий своего существования, к результатам собственной социальной самоорганизации и развитию технологий деятельности, а также в превращении наиболее успешных и эффективных технологий этой адаптации в нормативно-ценностные установки коллективного бытия людей» (Флиер, 1995: 72-73).

В контексте социологии $\Lambda$. $\Lambda$. Шпак рассматривает адаптацию в том числе через категорию адаптированности как «состояние субъекта, которое позволяет ему чувствовать себя свободно в социально-культурной среде, включаться в основную деятельность, чувствовать изменения в привычном социально-культурном окружении, углубляться во внутриличностные духовные проблемы, обогащая собственный мир путем более совершенных форм и способов социокультурного взаимодействия» (Шпак, 1992: 127).

В контексте педагогики созвучна нашему пониманию социальной адаптации студентов как движения личности к достижению гармоничного взаимодействия со средой трактовка Г. В. Кузнецовой: «...адаптация - это процесс взаимодействия человека с окружающей средой, в результате которого у него возникают модели и стратегии поведения, адекватные меняющимся в этой среде условиям» (Кузнецова, 2013: Электронный ресурс).

А. 3. Гостева, А. А. Еленская выделяют такие аспекты адаптации, как профессиональная, социальная, психологическая, дидактическая, биологическая (Гостева, Еленская, 2013).

Таким образом, педагогический результат адаптации студентов можно оценить через достижение студентом-первокурсником индивидуального максимально возможного уровня профессионального самоопределения, самоуважения, самоактуализации в учебной и внеучебной деятельности, эмоциональной стабильности и психологического комфорта.

Анализ научной литературы позволил выявить наиболее важные факторы, затрудняющие процесс адаптации первокурсников. Так, некоторые исследователи пишут об отсутствии навыков самоорганизации в учебном процессе, самообразования, недостаточном уровне знаний по общеобразовательным предметам; затруднениях с установлением контактов в новом коллективе; отсутствии представлений о перспективах работы по выбранной специальности и др. (Шолохова, Чикова, 2014; Яковлева, 2000).

В свою очередь, наша собственная практика и опыт коллег показывают, что качественная организация учебной деятельности первокурсников, эффективная содержательная деятельность кураторов, участие в процессе адаптации первокурсников органов студенческого самоуправления совместно с психологической службой в период адаптации, вовлечение студентов-первокурсников во внеучебную деятельность позволяют обеспечить әффективность адаптационного процесса первокурсников (Жегульская, 2014; Семенова, 2011; Старосотникова, 2010). 


\section{АААПТАЦИЯ КАК ЭВОАЮЦИОННЫЙ ПРОЦЕСС}

Стремясь выявить социально-педагогическую и психологическую сущность феномена адаптации, мы представим это время в жизни студентов как период эволюционных преобразований, полагая вслед за И. И. Шмальгаузеном, что эволюция детерминирована сменой условий существования как в пространстве, так и во времени (Шмальгаузен, 1968). Эволюционность процессу адаптации первокурсников придает формирование у первокурсников принципиально новых знаний, представлений, ценностных ориентаций и навыков вследствие освоения и завоевания новой для себя адаптивной среды. За этой эволюцией интересно наблюдать, и в то же время с позиций педагогики очевидно, что процесс должен быть целенаправленным, планируемым, управляемым и контролируемым. В живой природе, по мнению И. И. Шмальгаузена, среда не имеет никакого замысла об эволюционирующем организме, ничего не знает о нем, следовательно, и не стремится к его улучшению, и, напротив, организм, узнавая среду, адаптируясь в ней, берет из нее то, что ему нужно (исходя из своих потребностей), и защищается от того, что ему вредно или опасно (там же). Важно, чтобы «среда» образовательного учреждения, в которой адаптируются первокурсники, в обобщенном смысле понимаемая нами как совокупность социальных, культурных, специально организованных психолого-педагогических условий, в результате которых происходит становление личности, была «настроена» на прием первокурсников.

Созвучен нашей позиции тезис М. В. Яковлевой: «Трудности адаптации находятся не в самом студенте, поэтому сущность адаптации рассматривается не как приспособление студентов к вузовскому обучению, а как “приспособление” вузовской среды к конкретному студенту. Аругими словами, можно лишь создавать условия для успешного протекания данного процесса» (Яковлева, 2000: 8).

Что мы понимаем под «настройкой» среды на прием первокурсников? Аля ответа на этот вопрос вернемся к понятию «эволюция», но посмотрим на нее глазами кибернетиков. Эволюция с точки зрения кибернетики может быть представлена как последовательность информационных процессов: накопление отбор, преобразование, передача.

«Каждая целостная информационная система (в нашем случае - это субъекты адаптации, т. е. первокурсники. - Т. С.), - пишет Ю. И. Оноприенко, - способна воспринять лишь ту информацию, которая соответствует ее актуальному состоянию (содержанию), любая другая системная информация будет восприниматься как “шум”, способный привести к дезорганизации системы, даже если эта информация играла важную роль в прежних состояниях той же системы» (Оноприенко, 2003: 85-86).

Итак, определим, какая информация и формы ее представления должны составлять основу программы адаптации первокурсников.

Аля изучения проблем адаптации студентов нами в 2015 г. было проведено исследование, в котором принимали участие студенты первого курса Ульяновского государственного технического университета (далее - УлГТУ) (год поступления 2014, общее количество 700 чел.). На первом этапе для выявления потребностей студентов в информации было опрошено 225 студентов - представителей факультета информационных систем и технологий, энергетического, радиотехнического, строительного факультетов (выборка соответствует генеральной совокупности). Также основу практической базы исследования составил анализ эссе о мотивах поступления в вуз, которое ежегодно пишут студенты, поступившие на первый курс.

Проведенный опрос и контент-анализ текстов эссе позволили нам определить несколько наиболее значимых тем. Студентов интересует в первую очередь, как устроен 
учебный процесс (какие условия предоставляются для реализации их потенциалов в науке, спорте, творчестве и, что самое важное, каковы перспективы будущей профессиональной деятельности). Аалее в списке тем: стипендиальное обеспечение и другие формы материальной поддержки студентов, возможности участия в программах по академическому обмену и международному сотрудничеству, порядок и случаи перевода с платного обучения на обучение за счет федерального бюджета, размышления на тему «Как научиться жить самостоятельно» и т. А.

Представляя университет как систему, первокурсников можно рассматривать как изменяющий эту систему элемент: каждая «единица жизни» - первокурсник - привносит в университет нечто новое, что заставляет его (университет) меняться, развиваясь. Перефразируя известное высказывание английского журналиста (эссеиста) Клайва Ажеймса «Последняя стадия адаптации продукта к рынку - это адаптация рынка к продукту», можно сказать, что «Последняя стадия адаптации первокурсника к вузу - это адаптация вуза к первокурснику».

Мы предложили связать среду и субъект адаптации двумя линиями связи: прямой линией управляющих сигналов и линией обратной связи, передающей во внешнюю среду информацию о действительном состоянии системы (университета глазами первокурсников как новых элементов среды). Так в Ульяновском государственном техническом университете в 2010 г. родились два проекта: конкурс творческих работ «Университет, в котором я хочу учиться» и «Академия проектного менеджмента». В результате реализации первого проекта появляется банк идей, в результате второго команды, готовые к их осуществлению.

\section{ПРОГРАММА СОЦИОКУИБТУРНОЙ АААПТАЦИИ СТУАЕНТОВ}

ПЕРВОГО КУРСА В СОЦИААЬНО-ПЕААГОГИЧЕСКОМ ПРОСТРАНСТВЕ ВУЗА

В течение 10 лет в Ульяновском государственном техническом университете проходила апробацию, шлифовалась и совершенствовалась Программа социокультурной адаптации студентов первого курса в социально-педагогическом пространстве вуза, охватывающая студентов всех факультетов (средняя численность участников программы - 600 чел.). Есть устойчивый эффект от ее реализации в вузе, проявляющийся в активности студентов во всех направлениях деятельности: в учебе, науке, творчестве, спорте, а значит, есть возможность поделиться опытом с коллегами.

Программа реализуется совместно со студенческими объединениями, входящими в состав объединенного совета обучающихся. В таблице представлены направления и мероприятия программы.

Коллеги - организаторы воспитательной работы в вузах - справедливо зададут вопрос о мотивации студентов: «Что нужно сделать для того, чтобы появился интерес и желание приобщиться к содружеству студентов "Политеха"?» Одна из идей решения этой непростой задачи пришла из маркетинга, осуществляемого большими торговыми сетями. Что, если попробовать модифицировать маркетинговый ход с буклетом, наклейками и призами? Так появилась акция «Живи! Стремись! Учись в Политехе!» В нее включены мероприятия для первокурсников или с участием первокурсников. Кроме того, что все мероприятия интересны сами по себе, участие в проекте позволит каждому первокурснику заработать баллы для своего будущего портфолио.

На каждом мероприятии волонтеры студенческого совета УлГТУ выдают студенту первого курса наклейку: зрителю - номиналом 1 балл, участнику - номиналом 5 баллов. 
ПЕРЕЧЕНЬ МЕРОПРИЯТИЙ ПРОГРАММЫ ПО НАПРАВАЕНИЯМ АЕЯТЕАЬНОСТИ PROGRAM OF ADAPTATION FOR FIRST-YEAR STUDENTS, BY TYPES OF ACTIVITY

\begin{tabular}{|c|c|c|}
\hline Направление & Мероприятия & Cpoк \\
\hline \multirow{9}{*}{$\begin{array}{l}\text { Адаптация } \\
\text { студентов } \\
\text { первого курса } \\
\text { к учебному } \\
\text { процессу }\end{array}$} & Кураторские часы* & Сентябрь \\
\hline & $\begin{array}{l}\text { Встреча заместителей деканов по воспитательной работе } \\
\text { со студентами, проживающими в общежитиях }\end{array}$ & Сентябрь \\
\hline & $\begin{array}{l}\text { Реализация метода дифференцированного обучения. } \\
\text { Аополнительные образовательные курсы по общим } \\
\text { дисциплинам (математика, физика, химия и др.) }\end{array}$ & $\begin{array}{l}\text { Сентябрь - } \\
\text { декабрь }\end{array}$ \\
\hline & $\begin{array}{l}\text { Теоретические ознакомительные занятия по физической } \\
\text { культуре }\end{array}$ & Сентябрь \\
\hline & Неделя первокурсника в научной библиотеке университета & Сентябрь \\
\hline & $\begin{array}{l}\text { Информационные семинары на темы: «Все о стипендиях и иных } \\
\text { формах материальной поддержки студентов УлГТУ», «Порядок } \\
\text { и случаи перевода студентов с платной формы обучения на } \\
\text { обучение за счет средств федерального бюджета» }\end{array}$ & Сентябрь \\
\hline & $\begin{array}{l}\text { Общеуниверситетская олимпиада по программированию для } \\
\text { студентов первого курса (для выявления потенциальных } \\
\text { участников Центра спортивного программирования) }\end{array}$ & Октябрь \\
\hline & $\begin{array}{l}\text { Родительское собрание студентов первого курса, тема: «Анализ } \\
\text { результатов промежуточной аттестации» }\end{array}$ & Ноябрь \\
\hline & Тренинг от студенческого совета «Как сдавать первую сессию» & Ноябрь \\
\hline \multirow{5}{*}{$\begin{array}{l}\text { Адаптация } \\
\text { студентов } \\
\text { к новому } \\
\text { коллективу }\end{array}$} & Тренинг на командообразование «Веревочный курс» & Сентябрь \\
\hline & Торжественное мероприятие «Посвящение в первокурсники» & Сентябрь \\
\hline & $\begin{array}{l}\text { Конкурс творческих работ первокурсников «Университет, } \\
\text { в котором я хочу учиться» }\end{array}$ & Октябрь \\
\hline & $\begin{array}{l}\text { Встреча с активом студенческого совета университета } \\
\text { и профкома студентов }\end{array}$ & Сентябрь \\
\hline & Квест-игра «Найди клад Политеха»** & Октябрь \\
\hline \multirow{3}{*}{$\begin{array}{l}\text { Вовлечение } \\
\text { студентов } \\
\text { первого курса } \\
\text { в деятельность } \\
\text { молодежных } \\
\text { общественных } \\
\text { объединений }\end{array}$} & $\begin{array}{l}\text { Презентация деятельности центра культуры и досуга студентов } \\
\text { «олэкс». Концерт творческих коллективов }\end{array}$ & Сентябрь \\
\hline & Презентация деятельности спортивного клуба УлГТУ & Сентябрь \\
\hline & $\begin{array}{l}\text { Презентация деятельности студенческого информационного } \\
\text { центра (студенческое телевидение, студенческое радио, } \\
\text { пресс-центр и электронный журнал ULSTUDACK) }\end{array}$ & Сентябрь \\
\hline
\end{tabular}




\begin{tabular}{|c|c|c|}
\hline Направление & Мероприятия & Cрок \\
\hline & $\begin{array}{l}\text { Презентация деятельности молодежного православного клуба } \\
\text { «Преддверие» }\end{array}$ & Сентябрь \\
\hline & $\begin{array}{l}\text { Презентация деятельности клуба «Молодая семья Политеха», } \\
\text { Школы молодых родителей }\end{array}$ & Сентябрь \\
\hline & $\begin{array}{l}\text { Презентация деятельности студенческого научного сообщества } \\
\text { «Наука } 2.0 »\end{array}$ & Октябрь \\
\hline & $\begin{array}{l}\text { Презентация деятельности студенческой комиссии по оценке } \\
\text { качества образования }\end{array}$ & Октябрь \\
\hline & $\begin{array}{l}\text { Презентация деятельности волонтерского центра УлГТУ } \\
\text { и Академии проектного менеджмента }\end{array}$ & Октябрь \\
\hline \multirow{5}{*}{$\begin{array}{l}\text { Культурно- } \\
\text { массовые ме- } \\
\text { роприятия } \\
\text { для студентов } \\
\text { первого курса }\end{array}$} & $\begin{array}{l}\text { Неделя студенческого театра УлГТУ. В репертуаре театра пьесы: } \\
\text { В. Красногоров «Жестокий урок»; А. Володин «Аве стрелы», } \\
\text { Тәффи «Женский вопрос», В Жеребцов ЩПотомок» }\end{array}$ & Сентябрь \\
\hline & $\begin{array}{l}\text { Конкурс творческих работ (эссе), посвященных темам, } \\
\text { затрагиваемым в спектаклях студенческого театра }\end{array}$ & $\begin{array}{l}\text { Сентябрь - } \\
\text { октябрь }\end{array}$ \\
\hline & $\begin{array}{l}\text { Конкурс самодеятельного художественного творчества } \\
\text { студентов «Аебют первокурсника» }\end{array}$ & Октябрь \\
\hline & $\begin{array}{l}\text { Фестиваль самодеятельного художественного творчества } \\
\text { студентов «Студенческая осень» }\end{array}$ & Ноябрь \\
\hline & $\begin{array}{l}\text { Студенческий бал, посвященный Международному дню } \\
\text { студентов }\end{array}$ & Ноябрь \\
\hline \multirow{4}{*}{$\begin{array}{l}\text { Спортивные } \\
\text { мероприятия } \\
\text { Научные } \\
\text { мероприятия }\end{array}$} & Спартакиада первокурсников по 17 видам спорта & $\begin{array}{l}\text { Сентябрь - } \\
\text { ноябрь }\end{array}$ \\
\hline & $\begin{array}{l}\text { Семинар с участием приглашенных специалистов областного } \\
\text { бизнес-инкубатора «Школа молодежного предпринимательства» }\end{array}$ & Октябрь \\
\hline & Студенческая научно-практическая конференция & Апрель \\
\hline & $\begin{array}{l}\text { Академия проектного менеджмента (обучающие семинары } \\
\text { и тренинги по социальному проектированию) }\end{array}$ & $\begin{array}{l}\text { Октябрь - } \\
\text { май }\end{array}$ \\
\hline \multirow[t]{2}{*}{$\begin{array}{l}\text { Профилакти- } \\
\text { ческие } \\
\text { мероприятия }\end{array}$} & $\begin{array}{l}\text { Семинары с участием приглашенных специалистов Федеральной } \\
\text { службы по контролю за незаконным оборотом наркотиков по } \\
\text { Ульяновской области }\end{array}$ & Октябрь \\
\hline & $\begin{array}{l}\text { Проведение анкетирования студентов по вопросу информиро- } \\
\text { ванности о причинах возникновения и последствиях социально } \\
\text { негативных явлений }\end{array}$ & $\begin{array}{l}\text { Октябрь - } \\
\text { ноябрь }\end{array}$ \\
\hline
\end{tabular}




\begin{tabular}{|c|c|c|}
\hline \multirow[t]{3}{*}{ Направление } & Мероприятия & Cpок \\
\hline & $\begin{array}{l}\text { Семинары с участием приглашенных специалистов Ульяновского } \\
\text { областного СПИА-центра }\end{array}$ & Октябрь \\
\hline & $\begin{array}{l}\text { Семинары с участием приглашенных специалистов аппарата } \\
\text { уполномоченного по противодействию коррупции } \\
\text { в Ульяновской области }\end{array}$ & Ноябрь \\
\hline \multirow{3}{*}{$\begin{array}{l}\text { Организаци- } \\
\text { онные меро- } \\
\text { приятия }\end{array}$} & Организация медицинского осмотра студентов первого курса & Сентябрь \\
\hline & $\begin{array}{l}\text { Организация выдачи пластиковых карточек для начисления } \\
\text { стипендии студентам первого курса }\end{array}$ & Сентябрь \\
\hline & $\begin{array}{l}\text { Встречи заместителей деканов по воспитательной работе со сту- } \\
\text { дентами, проживающими в общежитиях }\end{array}$ & $\begin{array}{l}\text { Сентябрь - } \\
\text { ноябрь }\end{array}$ \\
\hline
\end{tabular}

* Кураторские часы (всего 50 часов в год).

** Цель квест-игры «Найди клад Политеха» - помочь студентам-первокурсникам освоиться в лабиринтах корпусов университета. Освоить навигацию по территории университета помогают также внутривузовские соревнования по спортивному ориентированию.

Количество набранных баллов будет учитываться как проявление активной жизненной позиции при участии студента:

- в конкурсе на назначение специальной повышенной государственной академической стипендии, стипендий Президента Российской Федерации, Правительства Российской Федерации, Губернатора Ульяновской области и др. (при соответствии всем необходимым критериям соответствующих положений о назначении указанных стипендий);

- обучающегося с полным возмещением затрат - в конкурсе на перевод с платной на бюджетную форму обучения (при соответствии другим требованиям Порядка перевода студентов с платной на бесплатную форму обучения);

- обучающегося с полным возмещением затрат - в Программе губернатора Ульяновской области по материальной поддержке студентов, обучающихся с полным возмещением затрат.

Группа студентов, набравших наибольшее количество баллов, в количестве 20 человек ежегодно (начиная с 2009 г.) отправляется на экскурсию в Санкт-Петербург.

\section{ОЦЕНКА ЭФФЕКТИВНОСТИ РЕААИЗАЦИИ ПРОГРАММЫ}

Из общего количества студентов, включенных в реализацию программы, нами для анализа результатов были выбраны две экспериментальные группы, представляющие техническое и гуманитарное направления профессиональной подготовки (общее количество 350 чел.), и одна контрольная в количестве 125 чел. (студенты Института авиационных технологий и управления УлГТУ, где программа реализуется фрагментарно). Таким образом, общее количество участников в экспериментальных и контрольной группах составило 475 чел. Такая выборка достаточно адекватно отражает характерные качества, присущие всей генеральной совокупности, следовательно, является представительной. 
Необходимо подчеркнуть, что при выборе диагностических процедур мы, осознавая трудность прямой диагностики адаптации студентов в силу его интегральной природы, обосновывали выводы, опираясь на комплексную оценку, сопоставление полученных данных. Применение комплекса апробированных в педагогических экспериментах процедур оценки (опрос, анкетирование, включенное наблюдение, фокус-группы) позволило получить наиболее точный результат. Сопоставление начального и конечного результатов позволило сделать вывод об эффективности реализации программы.

Теоретически были определены критерии и показатели, иллюстрирующие процесс адаптации первокурсников в когнитивном, мотивационно-ценностном, деятельностном и рефлексивном компонентах.

Итак, в результате реализации мероприятий программы в экспериментальных группах наблюдаются следующие педагогические эффекты.

Изменяется иерархическая структура ценностных ориентаций дичности студентов. Находят осмысление ценности образования, профессии, саморазвития. Формируется осознанное отношение к учебе, появляется интерес и познавательная активность, опыт самостоятельной образовательной деятельности. К существенным результатам стоит отнести переход начальных представлений о будущей профессии в сознательную форму, когда происходит осознание и актуализация собственного потенциала. По результатам опроса, проведенного в ноябре 2014 г. студенческим комитетом по качеству образования, на вопрос: «Интересно ли вам учиться?» $-50,7 \%$ студентов ответили «скорее да, чем нет»; оценили свою заинтересованность в работе по специальности на $4-5$ баллов $65,7 \%$.

Отчетливо проявляется формирование коммуникативных навыков. Основу коммуникативного взаимодействия составляют субъект-субъектные отношения, выстраивается диалог, в обсуждении общих для академической группы тем прослеживается применение методики оценки себя и партнера как субъектов коммуникации. В академической группе происходит интериоризация групповых ценностей, выстраиваются коммуникативные стратегии каждого из членов группы на основе общих смыслов.

Методом включенного наблюдения в ходе открытых встреч первокурсников с дидерами студенческого самоуправления, администрацией вуза и представителями государственной исполнительной власти региона мы выявляли динамику в формировании навыков саморегуляции поведения в ситуациях, когда необходимо обосновать свою мировоззренческую позицию, стремление к самообразованию и самосовершенствованию. Зафиксировано, что большинство студентов в экспериментальных группах $(64 \%)$ проявляют активность и самостоятельность в выводах и суждениях, обосновывают перспективы своей профессиональной деятельности в будущем.

В контрольной группе результаты существенно отличаются от результатов экспериментальных групп: студенты и по окончанию первого курса испытывают затруднения, в особенности в адаптации к учебной деятельности, профессиональном самоопределении, поиске своей роли и места в социальных проектах и программах, реализуемых объединенным советом обучающихся.

\section{ЗАКАЮЧЕНИЕ}

Отметим, что потенциальные способности личности, включая адаптацию, могут перейти в актуальное состояние только при проявлении личностной активности студента, отражающей его самостоятельную, индивидуальную позицию. 
Связь субъекта адаптации со средой должна носить взаимно преобразующий характер, первокурсники обязательно привнесут в образовательную среду новизну, придадут ей временно неустойчивое состояние изнутри. Извне среда подвергнется изменением под влиянием новых требований, предъявляемых к высшей школе в современных условиях инновационного технологического развития. Важно уловить эти изменения, регулируя и обновляя психолого-педагогические условия учебного процесса в соответствии с целями профессионального образования. В этом случае можно говорить об адаптации как об эволюционном процессе, когда каждое новое состояние по отношению к предшествующему является более совершенным в качественном отношении.

Чтобы развивать личность, сама образовательная среда должна каждый год становиться сложнее, ценнее, значительнее, наполняться новыми возможностями для реализации потенциала студентов в самореализации, профессиональном становлении, исходя из их потребностей.

\section{СПИСОК АИТЕРАТУРЫ}

Буянова, И. Б. (2005) Социокультурная адаптация выпускников сельских школ к условиям педагогического вуза : автореф. дис. ... канд. пед. наук. Саранск. 24 с.

Гостева, $\Lambda$. 3., Еленская, А. А. (2013) Проблема адаптации студентов первого курса в высшем учебном заведении (на примере АмГУ) // Вестн. Амурск. гос. ун-та. Вып. 54. С. 86-91.

Ермаченко, Н. А., Середа, В. А. (2012) Адаптация первокурсников к условиям обучения в УрГПУ // Инновации в науке. № 9. С. 52-61.

Жегульская, Ю. В. (2014) Социально-педагогическая адаптация студентов вуза культуры и искусств средствами культурно-досуговой деятельности : автореф. дис. ... канд. пед. наук. Челябинск. 26 с.

Кузнецова, Г. В. (2013) Адаптация первокурсников к вузовской среде [Электронный ресурс]// Социальная сеть работников образования «Наша сеть». 25 марта. URL: http://nsportal.ru/ vuz/ pedagogicheskie-nauki/library/2013/03/25/adaptatsiya-pervokursnikov-k-vuzovskoy-srede [архивировано в WebCite] (дата обращения: 29.05.2015).

Оноприенко, Ю. И. (2003) Эволюционная биология. Системно-информационный подход. Магадан. : СВНЦ АВО РАН. 230 с.

Семенова, В. Ю. (2011) Социокультурная адаптация современных студентов // Вестн. Казанск. гос. ун-та культуры и искусств. № 1. С. 49-52.

Старосотникова, В. Ю. (2010) Стратегии профессиональной адаптации студентов в социальном пространстве высших учебных заведений : автореф. дис. ... канд. соцол. наук. Нижний Новгород. $32 \mathrm{c}$.

Шмальгаузен, И. И. (1968) Кибернетические вопросы биологии. Новосибирск : Наука, Сибирское отделение. 224 с.

Шолохова, Г. П., Чикова, И. В. (2014) Адаптация первокурсников к условиям обучения в вузе и ее психолого-педагогические особенности // Вестн. Оренбургск. гос. ун-та. № 3 (164). C. 103-107.

Шпак, $\Lambda$. . (1992) Социокультурная адаптация: сущность, направление, механизмы реализации : дис. ... А-ра социол. наук. Кемерово. 398 с.

Флиер, А. Я. (1995) Культурогенез. М. : РИК. 128 с.

Яковлева, М. В. (2000) Педагогические основы адаптации первокурсников к обучению в вузе : автореф. дис. ... канд. пед. наук Улан-Удэ. 26 с. 
ADAPTATION OF FIRST-YEAR STUDENTS TO THE EDUCATIONAL

ENVIRONMENT OF AN INSTITUTION OF HIGHER EDUCATION AS A PERIOD

OF EVOLUTIONARY TRANSFORMATION

(THE CASE OF ULYANOVSK STATE TECHNICAL UNIVERSITY)

\section{T. L. STENINA}

(ULYANOVSK STATE TECHNICAL UNIVERSITY)

In this article, we examine the phenomenon of student adaptation in the context of pedagogics of the higher school as the result of pedagogical interaction between subjects of education in order to help students appropriate (interiorize) the values of professional education. As any other pedagogical process, student adaptation occurs within a certain space-time continuum known as 'environment'. The environment and the subject of adaptation are linked by two lines of communication - one sends operating signals to the subjects and the other receives feedback from them, thus distinguishing between action and its outcomes. Experience has shown that an adaptation system designed in this way makes it dramatically more efficient. In this system, an unconditional priority of the administration's opinion is impossible, while the feedback from students creates an opportunity of pedagogical interaction.

The article outlines the organization of the educational environment of an institution of higher education (HEI) in such a way as to encourage and help freshmen interiorize higher school values, follow the historically developed university traditions of student adaptation within the system of internal and external communication channels. Upon entering this novel environment, first-year students (freshmen) start interacting with it by joining in different types of activity.

Our analysis is based on examining the comprehensive "Program of sociocultural adaptation of first-year students in the social and pedagogical environment of an institution of higher education". Since 2009, this program has been implemented in Ulyanovsk State Technical University. An additional study covered 475 first-year students (majoring in engineering or the humanities). A specially designed set of assessment procedures (including opinion polls, questionnaires, participant observation and focus groups) helped refine the outcomes and define the criteria illustrating the process of freshmen's adaptation in its cognitive, motivational, activity-based and reflexive components.

A comparison between the initial and final outcomes of the study helped us draw a conclusion that the developed program has been implemented efficiently.

Keywords: Ulyanovsk state technical university; adaptation of students; first-year student (freshman); educational environment of institution of higher education (HEI)

\section{REFERENCES}

Buianova, I. B. (2005) Sotsiokul' turnaia adaptatsiia vypusknikov sel' skikb shkol k usloviiam pedagogicheskogo vuza [Sociocultural adaptation of rural school graduates to studying at a pedagogical institution of higher education] : Abstract of the diss. ... Candidate of Pedagogy. Saransk. 24 p. (In Russ.).

Gosteva, L. Z. and Elenskaia, D. A. (2013) Problema adaptatsii studentov pervogo kursa v vysshem uchebnom zavedenii (na primere AmGU) [Problem of freshmen's adaptation in an institution of higher education (The case of Amur State University)]. Vestnik Amurskogo gosudarstvennogo universiteta, no. 54, pp. 86-91. (In Russ.).

Ermachenko, N. A. and Sereda, V. A. (2012) Adaptatsiia pervokursnikov k usloviiam obucheniia $v$ UrGPU [Adaptation of freshmen to studying at Ural State Pedagogical University]. Innovatsii v nauke, no. 9, pp. 52-61. (In Russ.).

Zhegulskaya, Ju. V. (2014) Sotsial'no-pedagogicheskaia adaptatsiia studentov vuza kul'tury $i$ iskusstv sredstvami kul'turno-dosugovoi deiatel' nost $i$ [Social and pedagogical adaptation of students at a HEI specializing in culture and fine arts by means of culture and leisure activity] : Abstract of the diss. ... Candidate of Pedagogy. Chelyabinsk. 26 p. (In Russ.).

Kuznetsova, G. S. (2013) Adaptatsiia pervokursnikov k vuzovskoi srede [Adaptation of freshmen to the HEI environment]. Sotsial' naia set' rabotnikov obrazovaniia «Nasha set' ", March 25. [online] Available at: http://nsportal.ru/vuz/pedagogicheskie-nauki/library/2013/03/25/adaptatsiya-pervokursnikov-k-vuzovskoy-srede [archived in WebCite] (accessed 29.05.2015). (In Russ.). 
Onoprienko, Yu. I. (2003) Evoliutsionnaia biologiia. Sistemno-informatsionnyi podkbod [Evolutionary biology. Systemic and informational approach]. Magadan, SVNC DVO RAN [Publ. House of the North-East Scientific Center, Far Eastern Branch, RAS]. 230 p. (In Russ.).

Semenova, V. Yu. (2011) Sotsiokul'turnaia adaptatsiia sovremennykh studentov [Sociocultural adaptation of contemporary students]. Vestnik Kazanskogo gosudarstvennogo universiteta kul'tury i iskusstv, no. 1, pp. 49-52. (In Russ.).

Starosotnikova, V. Yu. (2010) Strategii professional' noi adaptatsii studentov $v$ sotsial' nom prostranstve vysshikb uchebnykh zavedenii [Strategies of professional adaptation of students in social space of HEIs] : Abstract of the diss. ... Candidate of Sociology. Nizhny Novgorod. 32 p. (In Russ.).

Shmalgauzen, I. I. (1968) Kiberneticheskie voprosy biologii [Cybernetic issues of biology]. Novosibirsk, Nauka Publ., Siberian Branch. 224 p. (In Russ.).

Sholokhova, G. P. and Chikova, I. V. (2014) Adaptatsiia pervokursnikov k usloviiam obucheniia v vuze i ee psikbologo-pedagogicheskie osobennosti [Adaptation of freshmen to studying at a HEI and its psychological and pedagogical features]. Vestnik Orenburgskogo gosudarstvennogo universiteta, no. 3 (164), pp. 103-107. (In Russ.).

Shpak, L. L. (1992) Sotsiokul'turnaia adaptatsiia: susbchnost', napravlenie, mebanizmy realizatsii [Sociocultural adaptation: Its essence, development course and mechanisms of implementation] : Diss. Doctor of Sociology. Kemerovo. 398 p. (In Russ.).

Flier, A. Ya. (1995) Kul' turogenez [Cultural genesis]. Moscow, Russian Institute of Culturology Publ. 128 p. (In Russ.).

Yakovleva, M. V. (2000) Pedagogicheskie osnovy adaptatsii pervokursnikov k obucheniiu v vuze [Pedagogical foundation of freshmen's adaptation to studying at a HEI] : Abstract of the diss. ... Candidate of Pedagogy. Ulan-Ude. 26 p. (In Russ.).

Submission date: 5.06 .2015 .

Стенина Татьяна Аьвовна - доктор педагогических наук, доцент, проректор по работе с молодежью Ульяновского государственного технического университета. Адрес: 432027, Россия, г. Ульяновск, ул. Северный Венец, д. 32. Тел.: +7 (8422) 77-83-34. Эл. aдpec: stl@ulstu.ru

Stenina Tatyana L'vovna, Doctor of Pedagogy, Associate Professor; Vice-rector for youth coordination, Ulyanovsk State Technical University. Postal address: 32 Severny Venets St., 432027 Ulyanovsk, Russian Federation. Tel: +7 (8422) 77-83-34. E-mail: stl@ulstu.ru 